\title{
Whole-genome Sequencing of Vibrio sinaloensis T47, a Tropical Marine Isolate with Quorum Sensing Properties
}

\author{
Nur Izzati Mohamad, Kah Yan How, Wai-Fong Yin, Kok-Gan Chan ${ }^{凶}$ \\ Division of Genetics and Molecular Biology, Institute of Biological Sciences, Faculty of Science, University of Malaya, Kuala Lumpur, 50603 \\ Malaysia.

\begin{abstract}
$\square$ Corresponding author: Kok-Gan Chan, Division of Genetics and Molecular Biology, Institute of Biological Sciences, Faculty of Science, University of Malaya, 50603 Kuala Lumpur, Malaysia. Email address: kokgan@um.edu.my

(c) Ivyspring International Publisher. This is an open access article distributed under the terms of the Creative Commons Attribution (CC BY-NC) license (https://creativecommons.org/licenses/by-nc/4.0/). See http://ivyspring.com/terms for full terms and conditions.
\end{abstract}

Published: 2017.03.09

\begin{abstract}
A large number of Vibrio sp. thrive in the marine environment and they are notable to cause food borne infection associated with undercooked seafood. In this study, we report the whole genome sequence of Vibrio sinaloensis T47 which was isolated from coastal marine water in Morib Beach, Hulu Selangor. The genome is made up of approximately 4.59 Mbp with 80 contigs and $46 \% \mathrm{G}+\mathrm{C}$ content. From the annotated genome, genes associated with quorum sensing (QS) were identified. This research provides a genetic basis for better understanding of QS pathway which contributes to the physiological traits of strain T47 to thrive in the marine environment.
\end{abstract}

Key words: Vibrio sinaloensis, whole genome sequencing, quorum sensing, autoinducer synthase, virulence factor

\section{Introduction}

Vibrio sp. is a very common bacterium which can be found in almost all water-borne environments including sea, estuary and fresh water. Vibrio sp. first made its debut into the scientific world through the discovery of bioluminescence properties. It was reported that Vibrio fischeri forms a symbiotic relationship with its host, the Hawaiian bobtail squid (Euprymna scolopes) and this underlying symbiosis is associated with quorum sensing (QS) [1]. QS is well known as a mechanism of virulence and colonization when the population in bacteria surpasses a threshold. This feature seems to be a common trait in the members of the genus Vibrio.

Since the development of advance taxonomical tools such as DNA-DNA hybridization, fluorescent amplified fragment length polymorphism and multilocus sequence analysis, the number of novel species from Vibrio family being discovered is constantly expanding $[2,3]$. Among the vast members of Vibrio genus, a number of them were demonstrated to possess QS abilities such as $V$. harveyi [4], V. cholera [5], and $V$. anguillarum [6]. There is mounting data suggesting that QS is responsible for many unique traits such as pathogenicity, swarming abilities and biofilm production $[7,8,9]$. In this work, we study on $V$. sinaloensis strain $\mathrm{T} 47$ which was isolated from a tropical marine in Morib Beach, Selangor ( $2^{\circ} 45^{\prime}$ 2.7" $\left.\mathrm{N}, 101^{\circ} 26^{\prime} 34.7^{\prime \prime} \mathrm{E}\right)$. A water sample was collected approximately $15 \mathrm{~cm}$ from the water surface.

$V$. sinaloensis was first documented by Gomez-Gil and colleagues [10] from the spotted rose snapper (Lutjanus guttatus) which causes infection and vibriosis. In fact, this bacterium is a major threat to the aquaculture sector due to its pathogenicity properties. 
The colonization of $V$. sinaloensis has been reported in crustaceans, for example, the white-leg shrimp, Litopenaeus vannamei [11]. Here, the sequencing strategy and data of the whole genome of strain T47 is presented to provide better understanding of the marine bacterium as well as insights to the physiological behaviors associated to QS activity.

$V$. sinaloensis strainT47 was cultured in aseptic condition on Luria Bertani Agar (LBA) with $3 \% \mathrm{NaCl}$ concentration $(\mathrm{w} / \mathrm{v})$ and incubated at $28^{\circ} \mathrm{C}$ overnight. The genomic DNA of strain T47 was extracted using QIAamp DNA Minikit (Qiagen, Germany) according to the manufacturer's instructions. The quality of the extracted DNA was measured using NanoDrop Spectrophotometer (Thermo Scientific) and Qubit 2.0 fluorometer (Life Technologies). Next, Nextera DNA Prep Kit (Illumina Inc., CA) was used to prepare the sequencing library followed by whole genome sequencing using a personal sequencer, Illumina MiSeq (Illumina Inc., CA). The total reads were assembled into 80 contigs with $43.8 \times$ coverage using CLC Genomic Workbench version 5.1 (CLC Bio, Denmark). The draft genome of strain T47 is made up of $4,599,504$ bp with G+C content of $46.12 \%$. The genome sequence has been deposited into GenBank under the accession number JXBJ00000000. The $16 \mathrm{~S}$ rDNA sequence used in identification of strain T47 [12] was also deposited into NCBI under accession number KR058860.

Based on 16S rDNA sequence, strain T47 was found to have more than $99 \%$ similarity to several Vibrio sp. such as $V$. variabilis, $V$. caribbeanicus, and $V$. sinaloensis. On the other hand, annotations of both functional and predicted genes were performed using the Integrated Microbial Genomes (IMG-ER) platform and with GOLD-ID Ga0063884 [13]. As shown in Table 1, the genome was resolved into 4,105 protein coding genes (CDs) and a total of 127 RNA genes which consist of 8 genes responsible for 5S rRNA synthesis, 5 genes for 16S rRNA synthesis, 6 genes for $23 \mathrm{~S}$ rRNA synthesis and 107 genes for tRNA. From the IMG-ER platform, cluster of orthologous groups (COG) categories showed that a large number of genes are responsible for basic life-sustaining needs of the bacterium. It was found that 310 genes were predicted to contribute to amino acid transport and metabolism, 245 genes are linked to carbohydrate transport and metabolism, 295 involves in signal transduction mechanisms, and 91 genes are related to the virulence and defense regulation (Table 2).

From the annotated genome sequences, a gene associated with QS was found in contig 14. The 1203 bp of luxM homologue is analogous to an $N$-acyl homoserine lactone (AHL) synthase, AinS, which can be also found in $V$. fischeri $[14,15]$. Hence, it is highly postulated that the autoinducer synthase LuxM is responsible for the production of signaling molecules in strain T47. In this study, the availability of the sequence could contribute to a better understanding of QS system and its role in $V$. sinaloensis.

Table 1. Genome features of $V$. sinaloensis strain T47

\begin{tabular}{|c|c|c|}
\hline Attributes & Number & $\%$ of Total \\
\hline DNA, total number of bases & $4,599,504$ & 100.00 \\
\hline DNA coding number of bases & $4,053,747$ & 88.13 \\
\hline DNA G + C number of bases & $2,121,494$ & $46.12^{1}$ \\
\hline DNA scaffolds & 80 & 100.00 \\
\hline Genes total number & 4232 & 100.00 \\
\hline Protein coding genes & 4105 & 97.00 \\
\hline RNA genes & 127 & 3.00 \\
\hline rRNA genes & 19 & 0.45 \\
\hline $5 \mathrm{~S}$ rRNA & 8 & 0.19 \\
\hline $16 \mathrm{~S}$ rRNA & 5 & 0.12 \\
\hline $23 \mathrm{~S}$ rRNA & 6 & 0.14 \\
\hline tRNA genes & 106 & 2.50 \\
\hline Other RNA genes & 2 & 0.05 \\
\hline $\begin{array}{l}\text { Protein coding genes with function } \\
\text { prediction }\end{array}$ & 3428 & 81.00 \\
\hline Pseudo genes & 65 & 1.54 \\
\hline Without function prediction & 677 & 16.00 \\
\hline Protein coding genes with enzymes & 1124 & 26.56 \\
\hline $\begin{array}{l}\text { Without enzymes but with candidate } \\
\text { KO based enzymes }\end{array}$ & 5 & 0.12 \\
\hline $\begin{array}{l}\text { Protein coding genes connected to } \\
\text { Transporter Classification }\end{array}$ & 614 & 14.51 \\
\hline $\begin{array}{l}\text { Protein coding genes connected to } \\
\text { KEGG pathways }\end{array}$ & 1310 & 30.95 \\
\hline Not connected to KEGG pathways & 2795 & 66.04 \\
\hline $\begin{array}{l}\text { Protein coding genes connected to } \\
\text { KEGG Orthology }(\mathrm{KO})\end{array}$ & 2448 & 57.84 \\
\hline Not connected to KEGG Orthology (KO) & 1657 & 39.15 \\
\hline $\begin{array}{l}\text { Protein coding genes connected to } \\
\text { MetaCyc pathways }\end{array}$ & 954 & 22.54 \\
\hline Not connected to MetaCyc pathways & 3151 & 74.46 \\
\hline Protein coding genes with COGs & 3085 & 72.90 \\
\hline Chromosomal Cassettes & 392 & - \\
\hline Biosynthetic Clusters & 8 & - \\
\hline Genes in Biosynthetic Clusters & 125 & 2.95 \\
\hline Fused Protein coding genes & 136 & 3.21 \\
\hline $\begin{array}{l}\text { Protein coding genes coding signal } \\
\text { peptides }\end{array}$ & 445 & 10.52 \\
\hline $\begin{array}{l}\text { Protein coding genes coding } \\
\text { transmembrane proteins }\end{array}$ & 1034 & 24.43 \\
\hline
\end{tabular}


Table 2. Cluster of orthologous groups for strain T47 IMG-ER platform

\begin{tabular}{lll}
\hline Name & Count & Percentage (\%) \\
\hline Amino acid transport and metabolism & 310 & 8.8 \\
Carbohydrate transport and metabolism & 245 & 6.95 \\
Cell cycle control, cell division, & 39 & 1.11 \\
chromosome partitioning & & \\
Cell motility & 135 & 3.83 \\
Cell wall/ membrane/ envelope biogenesis & 220 & 6.24 \\
Chromatin structure and dynamics & 1 & 0.03 \\
Coenzyme transport and metabolism & 173 & 4.91 \\
Defense mechanisms & 91 & 2.58 \\
Energy production and conversion & 198 & 5.58 \\
Extracellular structures & 49 & 1.39 \\
Function unknown & 207 & 5.87 \\
General function prediction only & 238 & 6.75 \\
Inorganic ion transport and metabolism & 177 & 5.02 \\
Intracellular trafficking, secretion and & 77 & 2.19 \\
vesicular transport & & \\
Lipid transport and metabolism & 122 & 3.48 \\
Mobilome: prophages and transposons & 12 & 0.34 \\
Nucleotide transport and metabolism & 93 & 2.64 \\
Posttranslational modification, protein & 162 & 4.6 \\
turnover, chaperones & & \\
RNA processing and modification & 1 & 0.03 \\
Replication, recombination and repair & 120 & 3.41 \\
Secondary metabolites biosynthesis, & 64 & 1.82 \\
transport and catabolism & & \\
Signal transduction mechanisms & 295 & 8.37 \\
Transcription & 257 & 7.29 \\
Translation, ribosomal structure and & 240 & 6.81 \\
biogenesis & & \\
Not in COG & 1147 & 27.1 \\
\hline & & \\
\hline
\end{tabular}

\section{Nucleotide sequence accession numbers}

The draft genome sequence of $V$. sinaloensis strain T47 can be obtained from GenBank under the accession number JXBJ00000000. This version described in the paper is the first version, JXBJ00000000. The GenBank accession number for 165 rDNA nucleotide sequence for strain T47 is KR058860. This version described in the paper is the first version, KR058860.

\section{Acknowledgement}

This work was supported by the High Impact Research Grants, University of Malaya (UM-MOHE HIR Grant UM.C/625/1/HIR/MOHE/CHAN/14/1, No. H-50001-A000027; UM-MOHE HIR Grant UM.C/ 625/1/HIR/MOHE/CHAN/01, No. A000001-50001) awarded to Kok-Gan Chan which are gratefully acknowledged.

\section{Competing Interests}

The authors have declared that no competing interest exists.

\section{References}

1. Lupp C, Urbanowski M, Greenberg EP, Ruby EG. The Vibrio fischeri quorum-sensing systems ain and lux sequentially induce luminescence gene expression and are important for persistence in the squid host. Mol Biol. 2001; 50(1): 319-331

2. Thompson FL, Hoste B, Vandemeulebroecke K, Swings J. Genomic diversity amongst Vibrio isolates from different sources determined by fluorescent amplified fragment length polymorphism. Syst Appl Microbiol. 2001; 24: 520-538

3. Pascual J, Macián MC, Arahal DR, Garay E, Pujalte MJ. Multilocus sequence analysis of the central clade of the genus Vibrio by using the $16 \mathrm{~S}$ rRNA, rezA, pyrH, rpoD, gyrB, rctB and toxR genes. Int J Syst Evol Microbiol. 2010; 60: 154-165

4. Henke JM, Bassler BL. Three parallel quorum-sensing systems regulate gene expression in Vibrio harveyi. J Bacteriol. 2004; 186(20): 6902-6914

5. Cámara M, Hardman A, Williams P, Milton D. Quorum sensing in Vibrio cholerae. Nat Gen. 2002; 32: 217-218

6. Milton DL, Hardman A, Cámara M, Chhabra SR, Bycroft BW, Stewart GS, Williams P. Quorum sensing in Vibrio anguillarum: characterization of the vanI/vanR locus and identification of the autoinducer N-(3-oxodecanoyl)-L-homoserine lactone. J Bacteriol. 1997; 179(9): 3004-3012

7. Waters CM, Bassler BL. The Vibrio harveyi quorum-sensing system uses shared regulatory components to discriminate between multiple autoinducers. Genes Dev. 2006; 20: 2754-2767

8. Henares $\mathrm{BM}, \mathrm{Xu} \mathrm{Y}$, Boon EM. A nitric oxide-responsive quorum sensing circuit in Vibrio harveyi regulates flagella production and biofilm production. Int J Mol Sci. 2013; 14(8): 16473-16484

9. Milton DL, Chalker VJ, Kirke D, Hardman A, Cámara M, Williams P. The LuxM homologue VanM from Vibrio anguillarum directs the synthesis of $\mathrm{N}$-(3-hydroxyhexanoyl) homoserine lactone and N-hexanoylhomoserine lactone. J Bacteriol. 2001; 183(12): 3237-3247

10. Gomez-Gil B, Fajer-Avila E, Pascual J, Macian MC, Pujalte MJ, Garay E, Roque A. Vibrio sinaloensis sp. nov. isolated from the spotted rose snapper, Lutjanus guttatus Steindachener, 1869. Int J Syst Evol Microbiol. 2008; 58: 1621-1624

11. del Carmen Flores-Miranda M, Luna-González A, Córdova AI Fierro-Coronado JA, Partida-Arangure BO, Pintado J, González-Ocampo HA. Isolation and characterization of infectious Vibrio sinaloensis strains from the Pacific shrimp Litopenaeus vannamei (Decapoda: Penaeidae). Rev Biol Trop. 2012; 60(2): 567-576

12. Tan PW, Tan WS, Muhamad Yunos NY, Mohamad NI, Adrian TGS, Yin WF, Chan KG. Short chain $N$-acyl homoserine lactone production in tropical marine Vibrio sinaloensis strain T47. Sensors (Basel). 2014; 14(7): 12958-12967

13. Markowitz VM, Mavromatis K, Ivanova NN, Chen IM, Chu K, Kyrpides NC. IMG ER: a system for microbial genome annotation expert review and curation. Bioinformatics. 2009; 2: 2271-2278

14. Gilson L, Kuo A, Dunlap PV. AinS and a new family of autoinducer synthesis proteins. J Bacteriol. 1995; 77: 6946-6951

15. Lupp C, Ruby EG. Vibrio fischeri LuxS and AinS: comparative study of two signal synthases. J Bacteriol. 2004; 186(12): 3873-3881 